Article

\title{
Parameterization of Radiation Fog-Top Height and Methods Evaluation in Tianjin
}

\author{
Tingting Ju ${ }^{1,2}$, Bingui $\mathrm{Wu}^{2,3, *,+}$, Hongsheng Zhang ${ }^{4}$ and Jingle Liu ${ }^{2}$ \\ 1 Navigation College, Dalian Maritime University, Dalian 116026, China; bnutingting@163.com \\ 2 Tianjin Key Laboratory for Oceanic Meteorology, Tianjin Meteorological Bureau, Tianjin 300074, China; \\ liujinglexxx@163.com \\ 3 Laboratory of Straits Meteorology, Xiamen Meteorology Bureau, Xiamen 361012, China \\ 4 Laboratory for Climate and Ocean-Atmosphere Studies, Department of Atmospheric and Oceanic Sciences, \\ School of Physics, Peking University, Beijing 100871, China; hsdq@pku.edu.cn \\ * Correspondence: tjwbgtjwbg@126.com; Tel.: +86-022-2335-2889 \\ + Current address: Tianjin Meteorological Bureau, No.100 Weather Station Road Hexi District, \\ Tianjin 300074, China.
}

Received: 25 March 2020; Accepted: 5 May 2020; Published: 8 May 2020

check for updates

\begin{abstract}
Different methods have been developed to estimate the fog-top height of radiation fog and evaluated using the measurements obtained from a 255-m meteorological tower located in Tianjin in 2016. Different indicators of turbulence intensity, friction velocity $\left(u_{*}\right)$, turbulence kinetic energy $(T K E)$, and variance of vertical velocity $\left(\sigma_{\mathrm{w}}{ }^{2}\right)$ were used to estimate the fog-top height, respectively. Positive correlations between the fog-top height and $u_{*}, T K E$, and $\sigma_{\mathrm{w}}{ }^{2}$ were observed, with empirical parameterization schemes $H=583.35 \times u_{*}^{1.12}, H=205.4 \times(T K E)^{0.68}$, and $H=420.10 \times\left(\sigma_{w}^{2}\right)^{0.51}$ being obtained. Among them, $\sigma_{\mathrm{w}}{ }^{2}$ is the most appropriate indicators of turbulence intensity to estimate the fog-top height. Compared with sensible flux and condensation rate, the new form of convective velocity scale $\left(\mathrm{W}_{*}\right)$ was the most appropriate indicator of buoyancy induced by radiative cooling, and the relationship $H=328.33 \times w_{*}^{1.34}$ was obtained. $\sigma_{\mathrm{w}}{ }^{2}$ and with $w_{*}$, which represents the intensity of turbulence and buoyancy, were used to estimate the fog-top height. The relationship $H=396.26 \times\left(\sigma_{\mathrm{w}}+0.1 \times w_{*}\right)-16$ was obtained, which can be used to accurately estimate the fog-top height. Moreover, the temperature convergence (TC) method was used to estimate the fog-top height; however, the results strongly rely on the threshold value.
\end{abstract}

Keywords: fog-top height; turbulence; radiative cooling; parameterization; surface measurements

\section{Introduction}

Fog is a boundary layer weather phenomenon composed of suspended water droplets or ice crystals, which reduces horizontal visibility to less than $1 \mathrm{~km}$ [1]. The low visibility due to fog events is a hazard to navigation, motor-vehicle accidents [2], plane delays [3], air crashes, and public health $[4,5]$, and the impact of fog has significantly increased because of increasing air, marine, and road transportation [6,7]. Therefore, more attention needs to be paid on fog.

Previous studies have shown that fog and low stratus significantly influence the earth's radiation balance [8,9]. Fog-top height (fog thickness) is considered to be very useful information for aircraft maneuvers, especially important for aircrafts having to land in foggy conditions. Moreover, there is no doubt about the importance of an accurate information of fog thickness for data assimilation of Numerical Weather Prediction (NWP) models, due to the significant impact of this parameter on the radiation budget close to the surface [10]. The estimation of observed fog-top height is important and useful for validation of model simulations [11], since comparisons between observed and simulated 
fog thickness cannot be performed in many cases due to no supplementary observational evidence of fog-top height. Moreover, the height of the fog top at the end of the mature phase is useful information for estimating the beginning and duration of the fog dissipation phase [12,13], with the thicker the fog layer, the more time is needed for fog dissipation. Therefore, it is also crucial to improve the nowcasting of fog dissipation [14]. However, many studies cannot provide information about observed fog-top height due to a lack of vertical measurements, and the height of fog top is usually difficult to determinate, since the fog-layer top cannot be observed from the surface.

The vertical extent of fog (fog thickness) ranges between a few meters and several hundred meters. Previous studies showed that turbulent mixing and radiative cooling are thought to be responsible for the increase in the depth of the fog. Numerical results showed that the fog-top height depends on the intensity of turbulence; the stronger the turbulence, the higher the top of the fog. In addition, some researchers have pointed out that the depth of fog is mainly due to the intensity of the inversion layer and that the inversion layer plays an important role in suppressing the vertical extension of this fog event; that is, the stronger the inversion, the lower the height of the fog-top. Moreover, both the concentration and size of aerosol particles in the polluted fog can affect urban fog thickness [15]. Therefore, fog-top height is closely related to turbulence and the upper inversion. However, the quantitative relationships between fog-top height and intensity of turbulence and inversion are ambiguous in the present study [16].

Many instruments and methods have been developed to determine the height of fog; satellite data, ground remote sensing instruments, and atmospheric sounding are usually used to provide approximations of fog-top height. In many case, temperature and humidity data from atmospheric sounding are used to estimate fog thickness $[17,18]$. The relative humidity profile is the most common and simple method to estimate the height of fog top; however, it is still uncertain to precisely define the fog top using the relative humidity threshold because of measurement uncertainties [19]. Cai et al. [20] defined the height above with a relative humidity that was smaller than $80 \%$, while Sorli et al. [21] set the threshold of relative humidity to $95 \%$, and $100 \%$ was used in Huang et al. [22]. Moreover, a mixing ratio of cloud water has also been used to determinate the height of fog top, with a threshold value $0.05 \mathrm{~g} \mathrm{~kg}^{-1}$ [23]. By considering the inversion intensity of temperature profiles and the $100 \%$ threshold on relative humidity profiles, the fog height can be estimated relatively accurately [24]. Moreover, the height of the fog top can be determined using virtual temperature profiles [11]. However, to determine fog-top height accurately, the measure points under and above the fog top should be dense. Therefore, there is discrepancy between the height of fog top estimated by atmospheric sounding and the real value, due to the vertical resolution of atmospheric sounding data. Moreover, ground remote sensing instruments are used to study radiation fog [25]; as an active sensor, it has advantages of high vertical resolution and detection sensitivity, however, the results are not satisfactory. A method of fog detection has been proposed by $\mathrm{Wu}$ et al. [26] and this method seems to be more reliable than the passive satellite measurements; however, it fails to identify dense fog layers because of the high signal attenuation.

Data and products from satellite have been widely used to detect fog or low clouds in foggy conditions [27]. Most applications retrieve fog-top height by comparing the satellite-derived infrared (IR) (infrared) temperature with temperature of soundings nearby. The premise of the scheme is that fog is related to an uplifted temperature inversion with inversion base height delimiting the fog top; therefore, the inversion base height is the fog top height [28]. Yi et al. [29] presented a novel method to retrieve low stratus/fog top heights using the infrared (IR) water vapor and split-window bands from geostationary (GEO) systems. However, the equations to retrieve inversion and thickness under foggy conditions were taken from Liu and Key [30], which were originally developed for clear sky situation. Thus, in future work, the adjustment of the new scheme should be developed to improve the adaptation of the original scheme. Despite its merit, the study also showed that a proper discrimination between low stratus and fog from satellite data remain challenging. A discrimination between fog at the ground and other low stratus situations from satellite data requires information on cloud vertical 
geometry to establish whether the cloud touches the ground. Cermak and Bendix [31] introduced a technique that allows for the discrimination between low stratus and (ground) fog on the basis of geostationary satellite imagery. The cloud base height is derived using a sub-adiabatic model of cloud microphysics. In this model, the cloud base is varied until model liquid water path (LWP) matches that retrieved from satellite data. The performance of this technique was shown to be good in comparison with METeorological Aerodrome Reports (METAR) data comprising 1030 satellite scenes. The main challenge in model development is to accurately quantify the deviation from the adiabatic profile. However, there are still misclassifications between low stratus and fog in some situations. In conclusion, it is very different to differentiate between fog and low clouds using satellite data [29,32].

As Marchand et al. [28] stressed in their review, fog-top height retrievals are a hitherto not yet a solved problem. In addition, satellite data, ground remote sensing instruments, and atmospheric sounding are expensive and not always available. Román-Cascón et al. [33] proposed two methods based on the surface data, and line correlations were observed between the height of fog top and surface friction velocity, and surface sensible flux. However, the results showed a relatively large bias and their methods were thus not appropriate to estimate the height of shallow fog.

In this study, different methods for estimation of fog-top height were evaluated and validated using the profile and atmospheric turbulence data obtained from a 255-m meteorological tower located in Tianjin. Moreover, two new estimated methods using the surface measurements were developed and evaluated. In Section 2, the information of the observation site, the instruments and data set are described. Moreover, several important parameters used in the study are calculated. In Section 3, different methods are used to estimate the fog thickness and compare with the observation results. A few new estimated methods based on turbulence intensity and radiative cooling are developed and validated using radiation fog events. In Section 4 , the conclusions are summarized.

\section{Data and Methods}

\subsection{Experiment Site and Data}

Tianjin is located in the eastern of North China Plain (NCP), with rather flat terrain. Furthermore, it is the largest coastal city in North China, with the Bohai Sea to the east. The results of Quan et al. [34] have shown that the mean occurrence number of fog events over the NCP is $11.4 \pm 6.9$ days $\mathrm{yr}^{-1}$. Long-term fog trends are observed at 13 weather stations in Tianjin from 1980 to 2010, showing that the total amount of fog has increased since 1980 [35]. The data used in this study were obtained from a meteorological tower at a height of $255 \mathrm{~m}$, located at the atmospheric boundary layer Meteorological Observation Station in the south of Tianjin city $\left(39.08^{\circ} \mathrm{N}, 117.21^{\circ} \mathrm{E}\right)$. There are no tall buildings around the tower in a radius of $50 \mathrm{~m}$, and heights of the surrounding buildings in the radius of $300 \mathrm{~m}$ are within $30 \mathrm{~m}$. Therefore, the observation site can represent the homogeneous urban underlying surface [36].

The data and instruments used in this study are presented in Table 1. The measurements of meteorological parameters (wind speed, wind direction, air temperature, etc.) were recorded automatically and continuously at a 10-min interval. The $10 \mathrm{~min}$ data were then converted to a $30 \mathrm{~min}$ moving average. The sampling frequency of atmospheric turbulence data is $10 \mathrm{~Hz}$, and a preprocessing was performed using Eddy Pro software (Advanced 4.2.1, LI-COR Biosciences, Inc. LI-COR, Lincoln, NE, USA). The preprocessing includes spike removal [37], double coordinate rotation [38], and trend removal. In addition, the block time average method was used in the trend removal process [39], with an average time interval of $30 \mathrm{~min}$. The results of Eddy Covariance (EC) depend on wind speed, stability parameter, and friction velocity; strict quality control was performed on the atmospheric turbulence data, for detailed criteria, please refer to Ye et al. [40] and Ren et al. [41]. Moreover, it should be noted that due to the limitation of the maximum height of the observation tower and because the fog-top heights of radiation fog were typically below $200 \mathrm{~m}$ [42], fog-top heights that were higher than $250 \mathrm{~m}$ are out of the scope of this paper. 
Table 1. List of instruments used in this study.

\begin{tabular}{|c|c|c|c|c|}
\hline Instrument & Mounting Height & Measurements & Sampling Interval & Accuracy \\
\hline $\begin{array}{c}\text { Cup and vane } \\
\text { anemometer } \\
\text { (Changchun, China) }\end{array}$ & 15 levels $^{a}$ & $\begin{array}{l}\text { Wind speed } \\
\text { Wind direction }\end{array}$ & $20 \mathrm{~s}$ & $0.1 \mathrm{~m} \mathrm{~s}^{-1}$ \\
\hline $\begin{array}{l}\text { Temperature and } \\
\text { relative humidity } \\
\text { probe (HMP45C, } \\
\text { CAMPBELL, USA) }\end{array}$ & 15 levels $^{\text {a }}$ & $\begin{array}{c}\text { Temperature } \\
\text { Relative humidity }\end{array}$ & $20 \mathrm{~s}$ & $\begin{array}{c}T: \pm 0.2{ }^{\circ} \mathrm{C} \\
R H: \pm 2 \%(0-90 \%) \\
\pm 5 \%(90-100 \%)\end{array}$ \\
\hline $\begin{array}{l}\text { Sonic anemometer- } \\
\text { thermometer (CSAT3, } \\
\text { CAMPBELL, USA) }\end{array}$ & $40,120,20 \mathrm{~m}$ & $\begin{array}{l}\text { Three-dimensional (3D) } \\
\text { wind components } \\
\text { Sonic virtual } \\
\text { temperature }\end{array}$ & $0.1 \mathrm{~s}$ & $\begin{array}{c}\mathrm{u}, \mathrm{v}:< \pm 0.04 \mathrm{~m} \mathrm{~s}^{-1} \\
w:< \pm 0.02 \mathrm{~m} \mathrm{~s}^{-1} \\
T_{\theta}: 0.01{ }^{\circ} \mathrm{C}\end{array}$ \\
\hline $\begin{array}{c}\mathrm{CO}_{2} / \mathrm{H}_{2} \mathrm{O} \text { Analyzer } \\
\text { (LI-7500, } \\
\text { LI-COR, USA) }\end{array}$ & $40,120,220 \mathrm{~m}$ & $\begin{array}{l}\text { Water vapor density } \\
\mathrm{CO}_{2} \text { concentration }\end{array}$ & $0.1 \mathrm{~s}$ & $\begin{array}{c}\mathrm{H}_{2} \mathrm{O}: 0.0047 \\
\mathrm{mmol} / \mathrm{mol} \\
\mathrm{CO}_{2}: 0.11 \mathrm{ppm}\end{array}$ \\
\hline $\begin{array}{l}\text { Visibility sensor } \\
\text { (Model 6000, } \\
\text { Belfort, USA) }\end{array}$ & $2 \mathrm{~m}$ & Visibility & $1 \mathrm{~min}$ & $\begin{array}{c} \pm 10 \%(5 \mathrm{~m}-10 \mathrm{~km}) \\
\pm 20 \%(10 \mathrm{~m}-20 \mathrm{~km})\end{array}$ \\
\hline $\begin{array}{l}\text { Net radiometer (CNR4, } \\
\text { Kipp \& Zonen, } \\
\text { Netherlands) }\end{array}$ & $40,120,220 \mathrm{~m}$ & $\begin{array}{l}\text { Downward/upward } \\
\text { short-wave and } \\
\text { long-wave radiation }\end{array}$ & $<18 \mathrm{~s}$ & $\begin{array}{l}\text { Short-wave: } \pm 5 \% \\
\text { long-wave: } \pm 10 \%\end{array}$ \\
\hline
\end{tabular}

\subsection{Calculation Methods}

Turbulence kinetic energy (TKE) and friction velocity $(u *)$ can be calculated according to Equations (1) and (2), respectively:

$$
\begin{gathered}
T K E=\frac{1}{2}\left(\overline{{u^{\prime}}^{2}}+\overline{{v^{\prime}}^{2}}+\overline{w^{\prime 2}}\right) \\
u_{*}=\left({\overline{u^{\prime} w^{\prime}}}^{2}+{\overline{v^{\prime} w^{\prime}}}^{2}\right)^{1 / 4}
\end{gathered}
$$

where $u^{\prime}, v^{\prime}$, and $w^{\prime}$ are fluctuating values respect to average values of the two horizontal wind speed $u$ and $v$ and vertical wind speed $w\left(\mathrm{~m} \mathrm{~s}^{-1}\right)$.

The turbulent exchange coefficient $K_{m}\left(\mathrm{~m}^{2} \mathrm{~s}^{-1}\right)$ can be calculated according to Equation (3):

$$
K_{m}=\frac{\kappa u_{*} z}{\varphi_{m}\left(\frac{z}{L}\right)}
$$

where $\mathrm{k}$ is the von Karman's constant and has a value of $0.4 ; z$ is the reference level and the observational height $(\mathrm{m}) ; L$ is the Obukhov length $(\mathrm{m}) ; z / L$ represents the stability factor; $\varphi_{m}$ is a dimensionless wind shear $[43,44]$.

The sensible heat $\left(H_{\mathrm{c}}, \mathrm{w} \mathrm{m} \mathrm{m}^{-2}\right)$ is calculated as follows:

$$
H c=\rho c_{\mathrm{p}} \overline{w^{\prime} T^{\prime}}=-\rho c_{p} u_{*} T_{*}
$$

where $\rho$ is the air density $\left(\mathrm{kg} \mathrm{m}^{-3}\right), c_{\mathrm{p}}$ the specific heat of air $\left(\mathrm{J} \mathrm{kg}^{-1} \mathrm{~K}^{-1}\right), \mathrm{T}^{\prime}$ is the fluctuation of air temperature $(\mathrm{K})$, and $T *$ is temperature scale $(\mathrm{K})$.

The parameter critical turbulent exchange coefficient $(K c)\left(\mathrm{m}^{2} \mathrm{~s}^{-1}\right)$ can be calculated according to Equations (5) and (6), for a shallow fog and a deep fog, respectively:

$$
\begin{aligned}
& K_{c}=1.38\left[\alpha \beta(p, T) C_{0}\right]^{1 / 2} H^{3 / 2} \\
& K_{c}=1.41\left[\alpha \beta(p, T) C_{t}\right]^{1 / 2} H^{3 / 2}
\end{aligned}
$$


where $\alpha=0.062$ is the gravitational settling parameter for radiation fog [45], $\beta(p, T) C_{0}(z)$ is the condensation rate per unit mass due to cooling of the air, and $C_{0}(z)=-(\partial T / \partial t)$ is the total local cooling rate, hereinafter referred to as cooling rate. The slope $\beta(p, T)$ can be expressed using the Clausius-Clapeyron equation as:

$$
\beta(p, T)=\frac{622 L_{v} e_{S}(T)}{R_{v} T^{2} p}
$$

where $L v$ is the latent heat of vaporization of water $\left(\mathrm{J} \mathrm{kg}^{-1}\right), e_{\mathrm{S}}$ represents the saturation vapor pressure (h pa), and $R_{\mathrm{v}}$ the gas constant for vapor $\left(\mathrm{J} \mathrm{kg}^{-1} \mathrm{~K}^{-1}\right) . C_{\mathrm{t}}$ is the cooling rate at the fog top $\left(\mathrm{K} \mathrm{h}^{-1}\right), H$ is the depth of the fog bank $(\mathrm{m})$. Moreover, the parameter can be used as a threshold; when $K_{\mathrm{m}}<K_{\mathrm{c}}$, the fog can persist at a fog mature phase [46].

The convective velocity scale $\left(w_{*}\right)$ represents the scaling velocity for the convective boundary layer, and can be calculated according to Equation (8) as follows:

$$
w_{*}=\left(\frac{g z_{i}}{\bar{\theta}}\left(\overline{w^{\prime} \theta^{\prime}}\right)_{s}\right)^{1 / 3}=\left(-\frac{g z_{i}}{\bar{\theta}} u_{*} \theta_{*}\right)^{1 / 3}
$$

where $z_{i}$ is the convective boundary layer height and can be estimated using the revised Carson scheme, by setting the initial boundary layer height to $150 \mathrm{~m}$ according to the potential temperature profile. The term $(\mathrm{g} / \bar{\theta})\left(\overline{w^{\prime} \theta^{\prime}}\right)$ represents the buoyancy heat flux.

The liner correlation between fog thickness and $u *$ is obtained in Román-Cascón et al. [33] and the relationship is:

$$
H=1369 \times u_{*}-28
$$

\section{Results and Discussions}

There are no unified fog criteria in previous literature, and different criteria have been used to identify fog events [47-49]. In this study, the criteria of fog were as follows [40]: (1) $R H \geq 90 \%$, (2) precipitation less than $1 \mathrm{~mm}$ per hour to eliminate the effect of precipitation (precipitation fog is out of our scope), and (3) the 10 -min visibility $\leq 1 \mathrm{~km}$. Moreover, we only focus on radiation fog in this study, which is the primary and most important inland fog form. Therefore, the 'fog' in this study refers to radiation fog, unless otherwise stated. All radiation fog events observed in 2016 were selected to develop new parameterizations of the fog-top height and evaluate different methods. The selected radiation fog events all formed in a nocturnal boundary layer and mainly due to radiative cooling at the surface. The wind speed was always low, and the durations of fog were between 7 and $18 \mathrm{~h}$, which is similar to the statistical result in Liu et al. [50]. In this study, the fog-top height was estimated using the relative humidity profile (not shown here), and the fog thickness was determined as the height above where the value of $R H$ was smaller than $90 \%$, and under where the value of $R H$ was larger than $90 \%$.

\subsection{Fog-Top Height Estimations Using Turbulence Intensity}

Previous studies [19] have shown that the whole fog life cycle is linked to the turbulence intensity. Though the role of turbulence in the formation of radiation fog remains controversial, turbulence within the fog layer is crucial for the exchange of material and energy, important for the development of fog. Therefore, turbulence mixing is considered to be the main mechanism that influences the fog-top height, and different described parameters related to turbulence intensity are used to estimate the fog-top height. In this study, friction velocity $(u *), T K E$, and variance of vertical velocity $\left(\sigma_{\mathrm{w}}{ }^{2}\right)$ were used to estimate the fog-top height, and the results were evaluated. The relationships between the fog-top $(H)$ height and $u_{*}, T K E$, and $\sigma_{\mathrm{w}}{ }^{2}$ are shown in Figure $1 \mathrm{a}, \mathrm{b}, \mathrm{c}$, respectively. A positive correlation between $H$ and $u_{*}$ is shown in Figure $1 \mathrm{a}$, and the relationship

$$
H=583.35 \times u_{*}^{1.12}
$$


can be obtained, with a coefficient of determination of $R^{2}=0.41$. The result confirmed the hypothesis that the turbulence intensity is crucial in the life cycle of fog and is closely linked to the fog-top height. Although there is a low turbulence intensity during the fog formation phase, turbulence mixing leads above air to be saturated conditions at the higher levels, and hence, to the development of fog bank, while strong turbulence leads to the fog collapse [12]. Therefore, the range of $u *$ in the scatterplot (Figure 1a) can be interpreted as the minimum and maximum turbulence intensity required for fog formation and dissipation, which are approximately 0.037 and $0.281 \mathrm{~m} \mathrm{~s}^{-1}$, respectively. The minimum turbulence intensity was slightly larger than that in Román-Cascón et al. [33], which were 0.025 and $0.030 \mathrm{~m} \mathrm{~s}^{-1}$ for different sites. The larger values of turbulence in this study were due to the sonic instrument installation height being $40 \mathrm{~m}$ in this study, which was $3 \mathrm{~m}$ or $1.5 \mathrm{~m}$ in Román-Cascón et al. [33]. However, the result verified that there was a threshold value of turbulence that influenced the formation of fog [51]. The maximum turbulence intensity in this study was much larger than those in Román-Cascón et al. [33]; this discrepancy was due to the sonic instrument installation height and the thickness of fog, with the thicker the fog, the stronger the turbulence the fog can endure [46]. The estimations with $H=1369 \times u_{*}-28$ (Equation (9)) obtained in Román-Cascón et al. [33] and similar linear correlation $H=502 \times u_{*}-4$ obtained in this study are also shown in Figure 1a. The results show there are obvious overestimations with $H=1369 \times u_{*}-28$, compared with the observations in Tianjin. There were few discrepancies between the estimations with $H=502 \times u_{*}-4$ and Equation (10), though the coefficient of determination of estimations with Equation (10) was a little higher. Therefore, Equation (10) obtained in this study seemed to be more appropriate to estimate the fog-top height in Tianjin, compared with Equation (9). The main reason of the discrepancies between the result in this study and Román-Cascón et al. [33] was that the relationship between fog-top height and $u_{*}$ in Román-Cascón et al. [33] was obtained by fitting seven or four mean values of $u_{*}$ associated to each discrete value of fog thickness, while the relationship in this study was obtained from a large amount of original values. In addition, the vertical resolution in Román-Cascón et al. [33] was low, seven layers under $200 \mathrm{~m}$ or four layers under $100 \mathrm{~m}$, which led to largely misestimate the actual fog-top height. The vertical resolution in this study was higher, 15 layers under $250 \mathrm{~m}$ and eight layers under $100 \mathrm{~m}$, which is favorable for the accurate estimation of fog-top height. Therefore, the relationship (Equation (10)) in this study was more appropriate to estimate the fog-top height, which represents the effect of turbulence on fog-top height and can show the temporal variations in the fog life cycle. However, there are some underestimations in large $u_{*}$ and overestimations for weak turbulence, which may be due to the effect of other meteorological parameters and large-scale atmospheric background fields.

Similar to the result of $u_{*}$, the estimations of fog-top height with TKE are shown in Figure $1 \mathrm{~b}$, and the relationship

$$
H=205.43 \times(T K E)^{0.68}
$$

with a coefficient of determination of $R^{2}=0.44$ was obtained, which indicates that TKE can be used to estimate the fog-top height. Compared with the estimations of the fog-top height with $u *$ and TKE, the estimations of the fog-top height with $\sigma_{\mathrm{w}}^{2}$ seem to be more agreed with the observations (Figure 1c). An obvious correlation between $H$ and $\sigma_{\mathrm{w}}{ }^{2}$ is shown in Figure 1c, and the relationship

$$
H=420.10 \times\left(\sigma_{w}^{2}\right)^{0.51}
$$

can be obtained, with a coefficient of determination of $R^{2}=0.53$. The results suggest that the variance of vertical velocity $\left(\sigma_{\mathrm{w}}{ }^{2}\right)$ is a more appropriate turbulence intensity indicator than the first two parameters, which can be used to estimate the fog-top height. Moreover, the minimum value of $\sigma_{\mathrm{w}}{ }^{2}$ is $0.0031 \mathrm{~m}^{2} \mathrm{~s}^{-2}$ in this study, that is, in the threshold range for fog formation $\left(0.002-0.005 \mathrm{~m}^{2} \mathrm{~s}^{-2}\right)$ obtained in Price [51], can prove the existence of a threshold value of turbulence for fog formation. Though there are some biases between estimations with turbulence and observations, the results in this section suggest the possibility of using turbulence to estimate the fog-top height. 

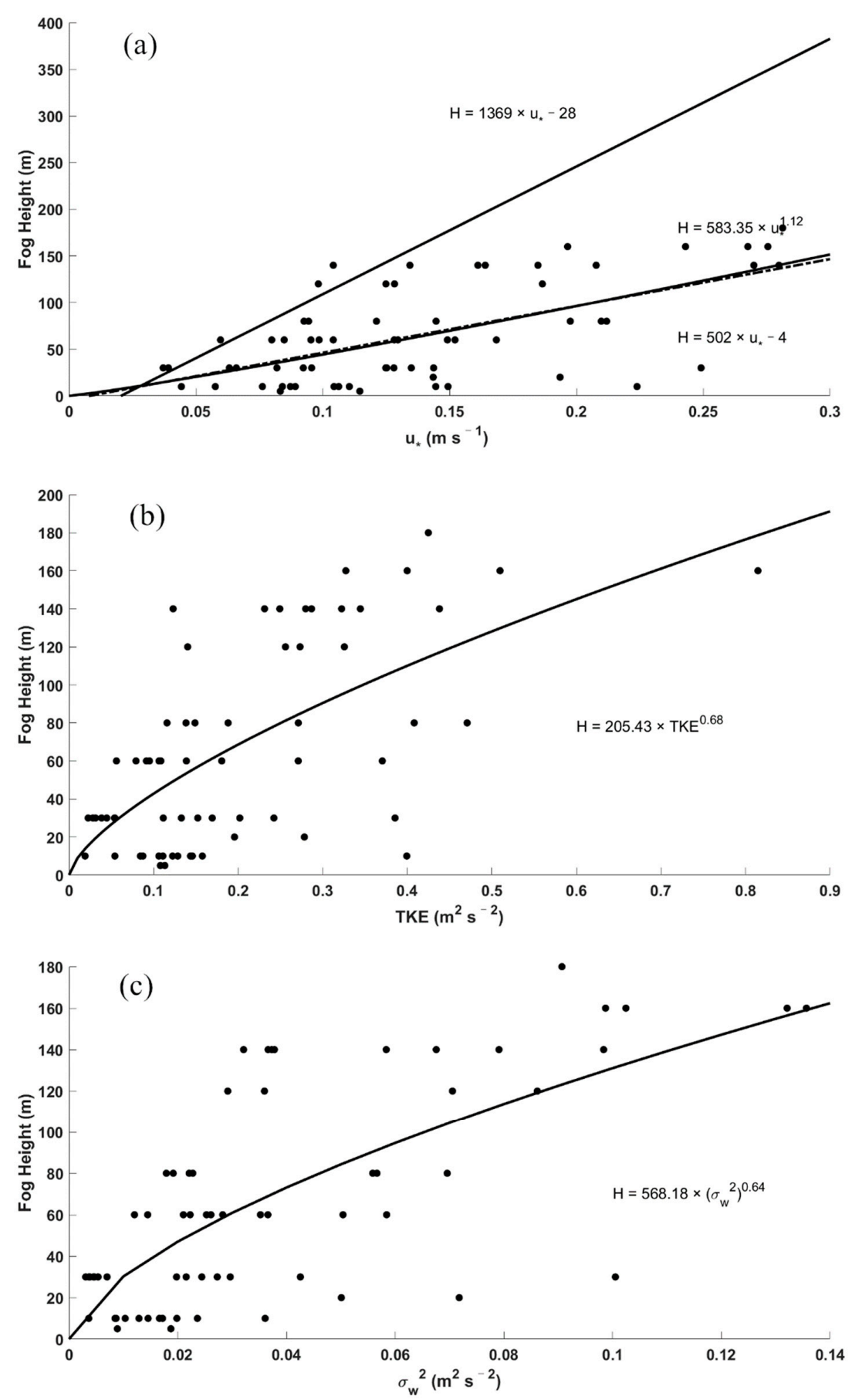

Figure 1. (a) Scatterplots of observations of fog-top height against the friction velocity. The bottom solid line denotes the relationship $H=583.35 \times u_{*}^{1.12}$, the bottom dashed line denotes the relationship $H=502 \times u_{*}-4$, and the upper solid line denotes the relationship $H=1369 \times u_{*}-28$. (b) Scatterplots of observations of fog-top height against TKE. The solid line denotes the relationship $H=205.43 \times(T K E)^{0.68}$. (c) Scatterplots of observations of fog-top height against the variance of vertical velocity $\left(\sigma_{\mathrm{w}}{ }^{2}\right)$. The solid line denotes the relationship $H=568.18 \times\left(\sigma_{w}^{2}\right)^{0.64}$.

\subsection{Fog-Top Height Estimations using Radiative Cooling}

Radiative cooling and heating impact the liquid water balance of fog, and therefore, play an important role in the evolution of fog. There are two main radiative processes that affect the evolution of fog: one is the longwave radiative cooling at the fog top, which produces liquid water by condensation; the other one is the heating of the ground by absorption of solar radiation, which can cause a sensible 
heat transfer to the fog, causing the fog dissipation [45]. Therefore, radiation fog often occurs at night, and dissipates a few hours after sunrise due to the solar radiation and turbulence. Therefore, condensation rate related to radiative cooling should to be closely related to fog-top height. However, the aim of this study was to estimate fog-top height only using the surface measurements, and previous result confirmed that an average or surface cooling rate can be used to replace the cooling at the fog top [46]. The condensation rate near the surface was used to estimate the fog-top height in this study; the result is shown in Figure 2a. The result shows that the fog-top height seems to be less related to the condensation rate near the surface, though fog optical depth is closely related to the condensation rate. Moreover, the relationship between the difference of fog-top height and condensation rate is shown in Figure $2 b$. The results show that the fog-top height increases (difference of fog-top height is larger than zero) when the condensation rate is larger than zero, while fog-top height decreases when condensation rate is smaller than zero. However, there are some cases where those are opposite to the conclusion that radiative cooling supports the development of fog. The main reason for this may be radiative heating and the difference of condensation rate between surface and fog top. Moreover, the result indicates that turbulence mixing seems to be more important for the development of fog-top height, though the condensation rate is crucial to the formation of fog and fog optical depth.
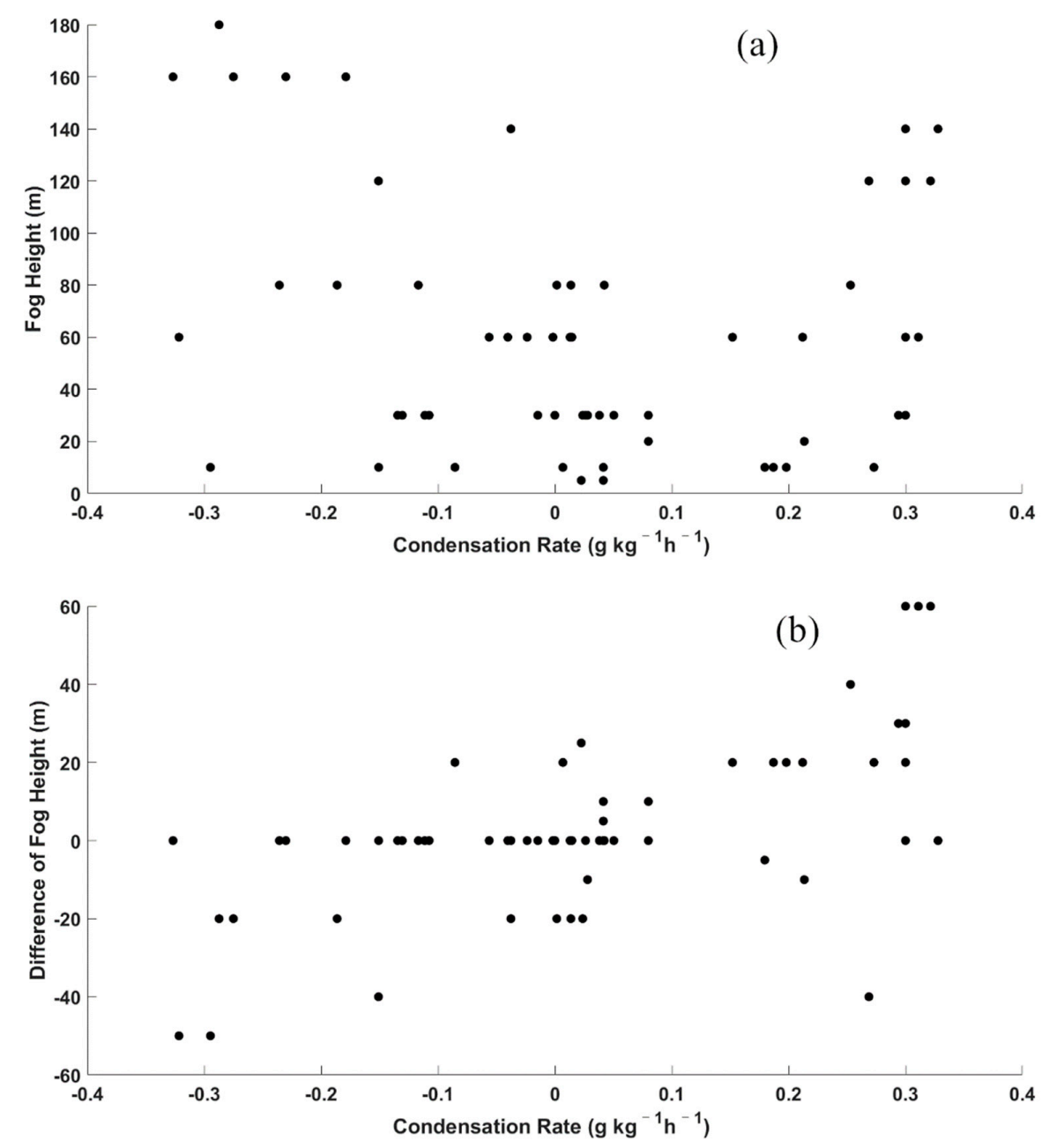

Figure 2. (a) Scatterplots of observations of fog-top height against the condensation rate. (b) Scatterplots of observations of the difference of fog-top height against the condensation rate.

Previous studies show that the fog-top height is influenced by the buoyancy generated by radiative cooling at the fog top, other than the turbulence. Therefore, sensible flux was chosen as the scaling parameter to represent the intensity of buoyancy and used to estimate the fog-top height. 
Compared with the estimations with turbulence intensity, the relationship between the fog-top height and sensible flux is complicated, and the scatter points are discrete, especially when the values of sensible flux are near zero (not shown here). It is obvious that the relationship between the fog-top height and sensible flux can be divided into two phases: the positive and negative sensible flux. Therefore, the relationship between the fog-top heights and absolute values of sensible flux is developed, and Equation (13) is obtained, with a coefficient of determination of $R^{2}=0.40$ (Figure 3a):

$$
H=29.49 \times|H c|^{0.45}
$$

Though the result indicates that the absolute values of sensible flux can be as a potential indicator of the fog-top height, there are some discrepancies between estimations and observations, especially for low sensible flux. The results are similar to the results in Román-Cascón et al. [33], with significantly dispersed distribution and larger error bars. Therefore, sensible flux may be not the appropriate indicator to represent the buoyancy and other described parameters should be sought out to represent the buoyancy induced by radiative cooling.

Once fog occur, fog stratification underwent a transition from thermally stable to weakly unstable, and the fog layer can be deemed to be well-mixed. To represent the intensity of buoyancy induced by radiative cooling at the fog top, a new form of the convective velocity scale $\left(w_{*}\right)$ was introduced. It should to be noted that new $w_{*}$ in this study is calculated according to Equation (8) with the absolute value of sensible flux. The new $w_{*}$ represents the buoyancy and neglects the sign, which means whether the sensible flux is negative or positive, it contributes to the mixing of fog layer and dry air, and leads to the development of fog layer.

The relationships between the $H$ and new $w_{*}$ are shown in Figure $3 \mathrm{~b}$ and a positive correlation between $H$ and $w_{*}$ is observed, with the relationship

$$
H=328.33 \times w_{*}^{1.34}
$$

being obtained, with a coefficient of determination of $R^{2}=0.44$. The results confirm that buoyancy induced by radiative cooling is a contributor to fog development, with the mixing between a fog layer and dry air. There are some bias between estimations and observations, which is because the fog bank near the surface is not always well-mixed fog; therefore, the effect of radiative cooling at the fog top cannot be represented by the new $w_{*}$. However, compared with sensible flux, the new $w_{*}$ is a more appropriate indicator of buoyancy induced by radiative cooling at the fog top, which can be used to calculate the fog-top height.

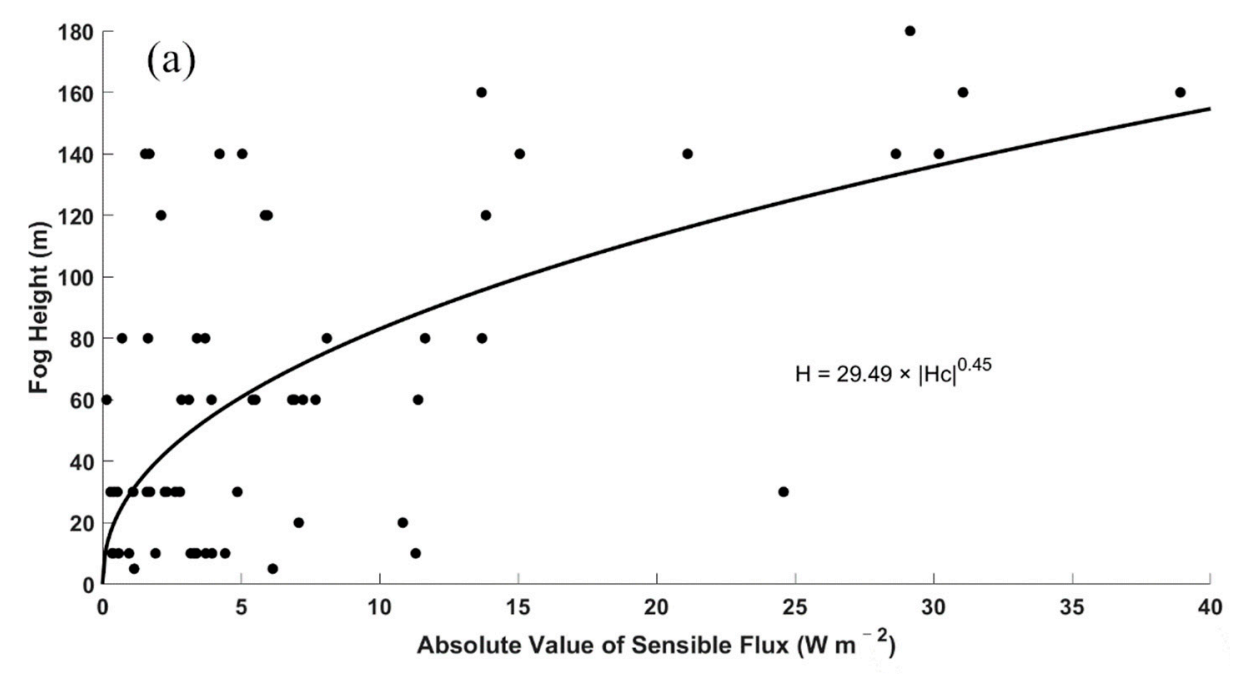

Figure 3. Cont. 


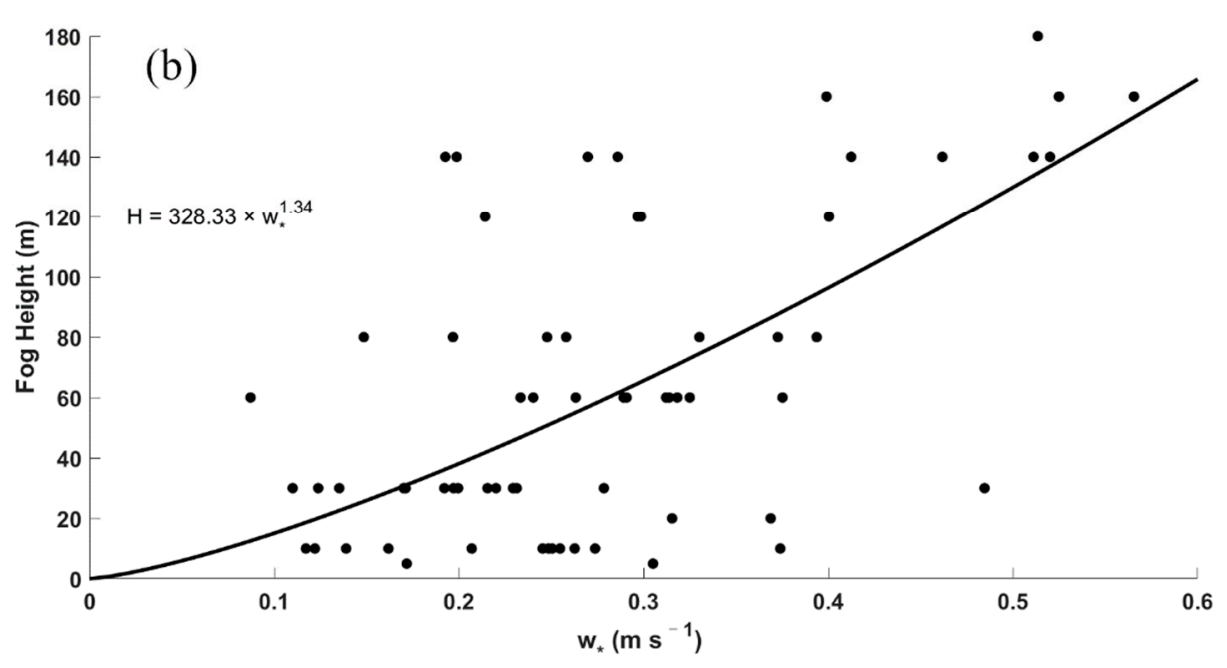

Figure 3. (a) Scatterplots of observations of fog thickness against the absolute values of sensible flux. The solid line denotes the relationship $H=29.49 \times|H c|^{0.45}$. (b) Scatterplots of observations of fog thickness against the convective velocity scale. The solid line denotes the relationship $H=328.33 \times w_{*}^{1.34}$.

\subsection{Fog-Top Height Estimations Using Turbulence and Radiative Cooling}

Based on the budget of liquid water content $(L W C)$, the asymptotic $L W C$ distribution was obtained, which is the result of the comprehensive effect among radiative cooling, droplet gravitational settling, and turbulence mixing in the liquid water budget of radiation fog. Based on the relationship between turbulence exchange coefficient and the fog thickness (Equation (6)), a new estimation method was developed:

$$
H_{\text {mod }}=a\left(\frac{k_{m}^{2}}{\beta(p, T) C_{t}}\right)^{\frac{1}{3}}
$$

where ' $a$ ' represents the coefficient constant and the result is shown in Figure 4. The relationship $H=1.45\left(\frac{k_{m}^{2}}{\beta(p, T) C_{t}}\right)^{\frac{1}{3}}+35$ was obtained, with a coefficient of determination of $R^{2}=0.26$, and the scatter points were extremely discrete. Obvious underestimations were observed; thus, this method was not appropriate to estimate the fog thickness. The large bias between the estimations and observations may be because Equation (15) was obtained from the balance condition at the fog mature phase, which is not suitable for estimations of the whole fog life cycle. In conclusion, there are two main causes of the poor estimations, one is that the asymptotic formulation is only suitable for the beginning of dissipation phase, and the other cause is that the relationship between condensation rate and the fog-top height is complicated and influenced by other factors, such as radiative heating and droplet gravitational settling.

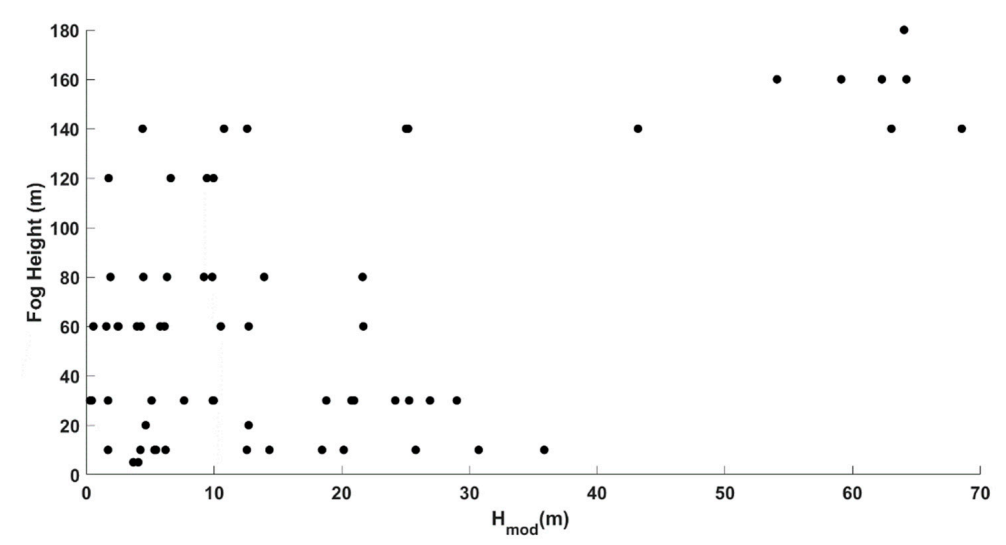

Figure 4. Scatterplots of observations of fog thickness against the estimations with Equation (15). 
Previous studies have shown that the development of fog can be attributed to turbulence mixing and radiative cooling at the fog top. In brief, the life cycle of fog depends mainly on the balance between radiative cooling and turbulence. Moreover, the results in Sections 3.1 and 3.2 suggest that $\sigma_{\mathrm{W}}{ }^{2}$ and $w_{*}$, with the same dimension, are the most appropriate parameters to represent the intensity of turbulence and buoyancy induced by radiative cooling, which are closely related to the fog-top height. Therefore, the fog-top height is estimated using the comprehensive parameters that include the two physics parameters. The relationship

$$
H=396.26 \times\left(\sigma_{w}+0.1 \times w_{*}\right)-16
$$

can be obtained, with a coefficient of determination of $R^{2}=0.55$. Some improvements can be observed (Figure 5), which confirms the previous conclusion that the fog life cycle is closely related to the turbulence intensity and radiative cooling. In conclusion, Equation (16) can be used to quantitatively estimate the fog-top height, using only the surface measurements. However, the estimation with Equation (16) cannot estimate the fog-top height perfectly, the scaling parameters $\sigma_{\mathrm{w}}{ }^{2}$ and $w_{*}$ also can be parameters to estimate the fog-top height. More scaling parameters represent the turbulence and radiation and different combinations of these scaling parameters should be found to estimate the fog-top height. Moreover, more radiation fog events are required to be used to estimate the fog-top height and verify the results.

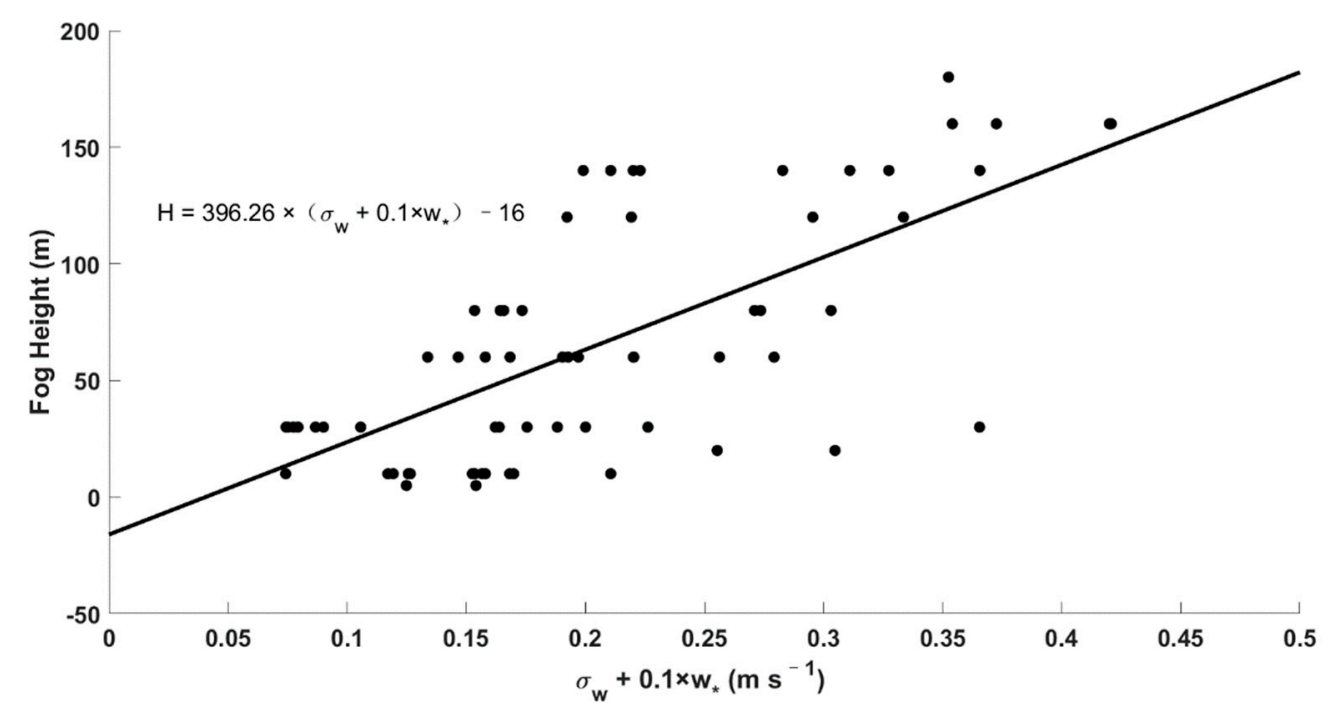

Figure 5. Scatterplots of observations of fog-top height against the variance of vertical velocity and the new $w_{*}$. The solid line denotes the relationship $H=396.26 \times\left(\sigma_{\mathrm{w}}+0.1 \times w_{*}\right)-16$.

\subsection{Fog-Top Height Estimation through Temperature Convergence (TC Method)}

The radiative cooling near the surface can lead to saturated air conditions at the ground, and hence, to the formation of fog droplets, and it may promote condensation in a supersaturated surface layer of sufficient depth, leading to fog formation. Once the fog first forms at the ground, the fog stratification undergoes a transition from thermally stable to weakly unstable [52]. The turbulent mixing within the fog causes the homogenization of the layer, and the mixing causes the convergence of temperatures, which leads the temperature of different heights to be a constant [11]. Previous studies have shown that the fog thickness can be estimated through the vertical temperature profile $[18,53]$. Considering the fog to be present at a certain height, when the difference between the potential temperature $\left(\theta_{z}\right)$ at the height and surface level $\left(\theta_{s}\right)$ is less than a threshold value $\left(\theta_{T}\right)$ :

$$
|\Delta \theta|=\left|\theta_{s}-\theta_{z}\right|<\theta_{T}
$$


The fog-top height is estimated to be the maximum height under where this criterion (in Equation (17)) is always satisfied. With the use of potential temperature, the height-related influence can be avoided. The determination of threshold value is crucial to estimate the fog thickness accurately. The uncertainty between two level temperatures is $0.4 \mathrm{~K}$, because the instrument-related uncertainty of temperature measurements is $0.2 \mathrm{~K}$. Small differences in potential temperatures are allowed between different heights, and this strategy has been used in Price [52] and Román-Cascón et al. [33], who used threshold value settings of $0.8 \mathrm{~K}$ and $1.2 \mathrm{~K}$, respectively. In this study, different threshold values were used in the estimations, and the threshold value was set to $1.2 \mathrm{~K}$ based on the estimated results of the fog thickness. The results of the fog thickness estimation versus the observations are shown in Figure 6a. The estimation results are consistent with the observations, with a coefficient of determination of $R^{2}=0.61$, which indicates that the TC method based on the differences in potential temperature is suitable for estimating the fog thickness, though there are some underestimations. Similar with the theory mentioned in Section 3.1, though the fog stratification is weakly unstable during the fog life cycle, atmospheric boundary structure may be different during the development phase and dissipation phase. Therefore, to estimate the fog thickness accurately, different threshold values were used, and the least square method was used to determine the $\theta_{\mathrm{T}}$ during the two phases. Ultimately, the threshold value during fog development phase and dissipation phase was set to $1.2 \mathrm{~K}$ and $1 \mathrm{~K}$, respectively. The relationship between the fog thickness estimated by TC method and the observation are divided into two phases: the development phase and the dissipation phase; the results are shown in Figure $6 \mathrm{~b}$. There was only a little improvement with the segmentation of threshold values, with a coefficient of determination of $R^{2}=0.64$; thus, the same threshold value can be used for the whole fog life cycle. The TC method was based on the theory that turbulent mixing within fog causes the temperature convergence, which results in the same value of different heights. However, the physics mechanisms during fog development and dissipation phase are different, with radiative cooling of the fog top and turbulence mixing leading to the increase of fog top, while the fog dissipation is the comprehensive effect of turbulence, radiative cooling of fog top, and entrainment of dry air. There may be a little difference in the degree of temperature convergence during the two phases; however, this is not observed in this study, which suggests more fog events are required to improve the estimations.
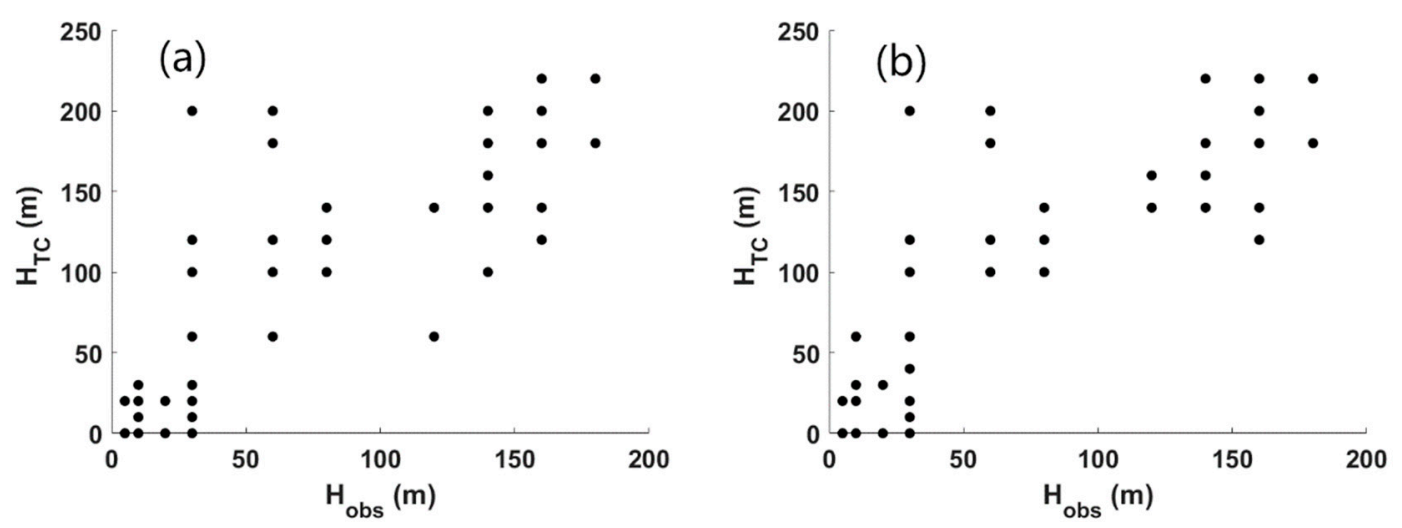

Figure 6. Scatterplots of observations of fog thickness against the estimation of fog thickness by temperature convergence (TC) method using in Equation (17), with (a) threshold value is set to $1.2 \mathrm{~K}$, (b) threshold value during fog development phase and dissipation phase is set to $1.2 \mathrm{~K}$ and $1 \mathrm{~K}$, respectively.

The virtual potential temperature seems to be more appropriate, because this parameter includes the effect of water vapor and liquid water content on temperature, which is more reasonable to describe the vertical distribution of temperature. Therefore, similar to in Equation (17), the difference between the virtual potential temperature at the height and surface level is used to determinate the fog top height. However, non-substantial differences are observed between using the potential temperature and virtual potential temperature (not shown here), which is consistent with the results of 
Román-Cascón et al. [33]. Moreover, previous studies also show that although some improvements have been made by using different thresholds for certain fog thickness estimations, it is always at the expense of a worsening of the results for other fog thickness; therefore, the determination of the threshold is still an intractable problem. Moreover, temperature convergence does not occur for shallow fog (not shown here), which is linked to strong thermal inversions and weak turbulence; therefore, the TC method is not valid. The result suggests that although the TC method may be inadequate for estimating the fog thickness of shallow fogs, it is still an appropriate method to estimate the deepen fog thickness larger than $100 \mathrm{~m}$, which is hazardous for transport.

\subsection{Comparisons of Fog-Top Height Estimations with Different Methods}

All parameterization schemes developed in this study and corresponding coefficients of determination are shown in Table 2 . The results confirm that $\sigma_{\mathrm{w}}{ }^{2}$ and $w_{*}$, with the same dimension, are the most appropriate indicators to represent the intensity of turbulence and buoyancy induced by radiative cooling. Therefore, the combination of $\sigma_{\mathrm{w}}{ }^{2}$ and $w_{*}$ (Equation (16)) is the best parameterization scheme developed in this study that can be used to estimate the fog-top height only using the surface measurement. Moreover, the TC method can be used to accurately estimate the fog-top height using the vertical profile data.

Table 2. All parameterization schemes developed in this study and corresponding coefficients of determination.

\begin{tabular}{ccc}
\hline Physical Mechanism & Parameterization Scheme & Coefficient of Determination $\left(\mathbf{R}^{2}\right)$ \\
\hline \multirow{2}{*}{ Turbulent mixing } & $H=583.35 \times u_{*}^{1.12}$ & 0.41 \\
& $H=205.43 \times(T K E)^{0.68}$ & 0.44 \\
Radiative cooling & $H=420.10 \times\left(\sigma_{w}^{2}\right)^{0.51}$ & 0.53 \\
& $H=29.49 \times|H c|^{0.45}$ & 0.40 \\
Turbulent mixing and radiative cooling & $H=328.33 \times w_{*}^{1.34}$ & 0.44 \\
Temperature convergence & $H=1.45\left(\frac{k_{m}^{2}}{\beta(p, T) C_{t}}\right)^{\frac{1}{3}}+35$ & 0.26 \\
& $H=396.26 \times\left(\sigma_{\mathrm{w}}+0.1 \times w *\right)-16$ & 0.55 \\
\hline
\end{tabular}

The fog-top height estimations of a thick fog and shallow fog with $H=1369 \times u *-28$ obtained in Román-Cascón et al. [33] (Equation (9)), $H=583.35 \times u_{*}^{1.12}$ (Equation (10)), $H=396.26 \times\left(\sigma_{\mathrm{w}}+0.1 \times w *\right)$ - 16 (Equation (16)) developed in this study, and the TC method (in Equation (17)) were compared and are shown in Figure 7. The results show that there were obvious overestimations with the relationship (Equation (9)) obtained in Román-Cascón et al. [33], for both thick and shallow fog, while the other three estimation methods all perform better in thick fog than in shallow fog. The results in Section 3.4 has pointed out that the TC method is not suitable for estimating the fog-top height of shallow fog, in which temperature convergence does not occur. Comparing the estimations in shallow fog with only $u *$ (Equation (10)) and the combination of $u_{*}$ and $w_{*}$ (Equation (16)), the estimations with the combination of $u *$ and $w *$ are closer to the observations, since the new parametrization scheme (Equation (16)) in this study considers the effect of radiative cooling and turbulence. Moreover, the new parametrization scheme (Equation (16)) can approximately simulate the temporal variation of fog-top height in the fog life cycle, though there are some underestimations. For thick fog, the TC method performed best, especially during fog formation and development phase. However, the TC method is expensive and not available in most areas. Moreover, to determine fog-top height with the TC method accurately, the measure points under and above the fog top should be dense. Therefore, the TC method can only be applied in a few sites, and the results strongly rely on the set of threshold value and vertical resolution of profile data. Comparing the estimations in thick fog with only $u_{*}$ and the combination of $u_{*}$ and $w_{*}$, there are better agreements between the estimations of the new parametrization scheme (Equation (16)) and observations, especially during the fog development phase. The new parametrization scheme 
can also simulate the temporal variation of fog-top height during the fog dissipation phase, though there are some underestimations. In conclusion, if only surface measurements are used to estimate the fog-top height in Tianjin, the new parametrization scheme (Equation (16)) developed by combining the effect of turbulence and radiative cooling in this study is more suitable compared with other methods. However, the parametrization schemes, except the TC method, cannot used to simulate the fog-top height during fog formation phase, during which the effect of turbulence on fog is ambiguous. Therefore, more effort should be made to improve our understandings of the effect of turbulence on fog life cycle.

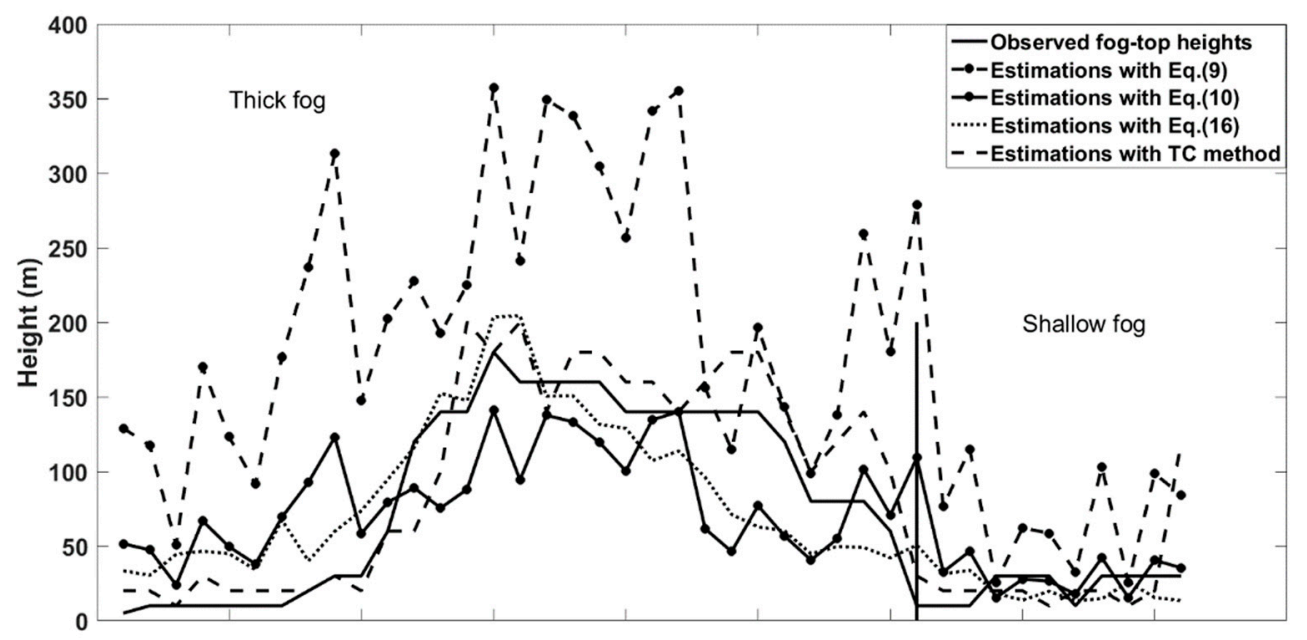

Figure 7. Observations of fog-top height, fog-top height estimations with $H=1369 \times u *-28$ (Equation (9)), $H=583.35 \times u_{*}^{1.12}$ (Equation (10)),$H=396.26 \times\left(\sigma_{\mathrm{w}}+0.1 \times w *\right)-16$ (Equation (16)), and the TC method (in Equation (17)) during a shallow and thick fog events in 2018.

\section{Conclusions}

In this study, different estimation methods for the fog-top height were developed and evaluated using all radiation fog events obtained from a 255-m meteorological tower located in Tianjin in 2016. The height of fog top was estimated using the relative humidity profile, and the threshold value of $R H$ is $90 \%$.

Different indicators of turbulence intensity, friction velocity $\left(u_{*}\right), T K E$, and variance of vertical velocity $\left(\sigma_{\mathrm{w}}{ }^{2}\right)$ were used to estimate the fog-top height, respectively, and the results were evaluated. The positive correlations between $H$ and $u_{*}$ and TKE were obtained, with empirical parameterization scheme $H=583.35 \times u_{*}^{1.12}$ and $H=205.43 \times(T K E)^{0.68}$. Compared with $u_{*}$ and $T K E$, the variance of vertical velocity $\left(\sigma_{\mathrm{W}}{ }^{2}\right)$ was the most appropriate turbulence intensity indicator for estimating the fog-top height, with the relationship $H=420.10 \times\left(\sigma_{w}^{2}\right)^{0.51}$ and a higher coefficient of determination being obtained. The results confirm that turbulence intensity is crucial to the life cycle of fog and is closely linked to the fog-top height. Moreover, the result confirmed the hypothesis that there are threshold values of turbulence that can influence the fog formation and dissipation.

Radiative cooling impacts the liquid water balance of fog and therefore plays an important role in the evolution of fog. Different indicators of radiative cooling, surface condensation rate, and sensible flux were used to estimate the fog-top height. The result in this study show that there is no obvious relationship between surface condensation rate and radiative cooling, which indicates that the condensation rate near the surface is not suitable to estimate the fog-top height, though it is positively related to fog optical depth. The estimation results with sensible flux, which was chosen as the described parameter representing the buoyancy generated by radiative cooling at the fog top, are discrete, with large biases. Consider the effect of buoyancy on vertical mixing, the absolute values of the sensible flux were used to associate with the fog-top height, and relationship $H=29.49 \times|H c|^{0.45}$ was obtained. However, the coefficient of determination was low $\left(R^{2}=0.40\right)$, which indicates the effect 
of radiative cooling at the fog top on fog-top height cannot be represented by sensible flux. To represent the buoyancy generated by radiative cooling at the fog top, a new form of convective velocity scale $\left(w_{*}\right)$, which was calculated with the absolute value of the sensible flux, was introduced and used to estimate the fog-top height. An obvious positive correlation between $H$ and new $w_{*}$ was observed, and the relationship $H=328.33 \times w_{*}^{1.34}$ was obtained, with a higher coefficient of determination. The results show that the new $w_{*}$ is more appropriate to represent the effect of radiative cooling at the fog top and can be used to calculate the fog-top height.

To comprehensively consider the effect of turbulence and radiative cooling, different combinations of different parameters were used to estimate the fog-top height. Based on the asymptotic LWC distribution at the fog mature phase, which was the result of comprehensive effect among radiative cooling, droplet gravitational settling, and turbulence mixing in the liquid water budget of radiation fog, a new method (Equation (16)) was presented to estimate the fog thickness. However, the estimations were extremely discrete, which indicates that this method is not appropriate to estimate the fog-top height in the whole fog life cycle. $\sigma_{\mathrm{w}}{ }^{2}$ and $w_{*}$, which are the most appropriate indicators of the intensity of turbulence and buoyancy induced by radiative cooling, and are used to estimate the fog-top height. The relationship $H=396.26 \times\left(\sigma_{\mathrm{w}}+0.1 \times w *\right)-16$ was obtained, with a higher coefficient of determination, which can be used to accurately estimate the fog-top height.

The fog thickness was also estimated through the vertical temperature profile, based on the theory that the fog layer is homogeneous, and the temperature at different heights within the fog is approximately constant, due to the turbulent mixing within fog. The fog-top height was estimated based on Equation (17) and threshold value was set to $1.2 \mathrm{~K}$. The results of fog thickness estimation using the TC method were consistent with the observations, with a coefficient of determination of $R^{2}$ $=0.61$. Moreover, there was a little improvement with the segmentation of threshold values, with a coefficient of determination of $R^{2}=0.64$. The virtual potential temperature was also introduced to determine the fog-top height, and few differences were observed between using the potential temperature and virtual potential temperature. In addition, the determination of threshold value was still an intractable problem and the TC method is not valid for shallow fog due to strong thermal inversions and weak turbulence. In brief, the TC method based on the differences in the potential temperature is suitable for estimating the fog thickness of deep fog.

This study compared the estimations of fog-top height with $H=1369 u_{*}-28$ obtained in Román-Cascón et al. [33], (Equation (9)), $H=583.35 \times u_{*}^{1.12}$ (Equation (10)), $H=396.26 \times\left(\sigma_{\mathrm{w}}+0.1 \times\right.$ $w_{*}$ ) -16 (Equation (16)) developed in this study, and the TC method (in Equation (17)) in a thick fog and shallow fog, respectively. The results showed that TC method performs best in thick fog, though it is not valid in shallow fog, which is not well-mixed. However, the TC method is expensive and not available in most areas, and the results strongly rely on the set of threshold values, which are different in different sites. Moreover, to determine fog-top height accurately, the measure points under and above the fog top should be dense. Therefore, the TC method can only be applied in a few sites, and the results strongly rely on the set of threshold and vertical resolution of profile data. There are better agreements between the estimations of the new parameterization scheme (Equation (16)) developed in this study and observations in both thick and thin fog, compared with the estimations of fog-top height with relationship (Equation (9)) in Román-Cascón et al. [33] and with only u* (Equation (10)). The results confirmed that the new parametrization scheme (Equation (16)) developed in this study, considering the comprehensive effect of turbulence and radiative cooling, can be widely used to estimate fog-top height only using the surface measurements.

It is not possible to state definitive conclusions after the analysis of several radiation fog cases at one site; nevertheless, the main factors, turbulence intensity and radiative cooling, that influence the fog-top height were determined. However, due to the limitation of observation height and vertical resolution, more research is required to seek for more appropriate and common parameters that can be used to estimate the fog-top height. 
Author Contributions: T.J.: Conceptualization, Methodology, Formal analysis, Writing-Original Draft. B.W.: Investigation, Writing-review and editing, Supervision. H.Z.: Conceptualization, Methodology. J.L.: Data curation. All authors have read and agreed to the published version of the manuscript.

Funding: This research was jointly funded by the National Natural Science Foundation of China (41675018, 41675135, 41705045), the Natural Science Foundation of Tianjin (17JCYBJC23400), and the Bohai Rim Regional Fund (QYXM201801).

Conflicts of Interest: The authors declare no conflict of interest.

\section{References}

1. WMO. International Meteorological Vocabulary; WMO: Geneva, Switzerland, 1992; pp. 1-276.

2. Bartok, J.; Bott, A.; Gera, M. Fog prediction for road traffic safety in a coastal desert region. Bound. Layer Meteorol. 2012, 145, 485-506. [CrossRef]

3. Huang, H.B.; Chen, C.Y. Climatological aspects of dense fog at Urumqi Diwopu International Airport and its impacts on flight on-time performance. Nat. Hazards 2016, 81, 1091-1106. [CrossRef]

4. Gautam, R.; Singh, M.K. Urban heat island over Delhi punches holes in widespread fog in the Indo-Gangetic Plains. Geophys. Res. Lett. 2018, 45, 1114-1121. [CrossRef]

5. Kim, H.J.; Collier, S.; Ge, X.L.; Xu, J.Z.; Sun, Y.L.; Jiang, W.Q.; Wang, Y.L.; Herckes, P.; Zhang, Q. Chemical processing of water-soluble species and formation of secondary organic aerosol in fogs. Atmos. Environ. 2019, 200, 158-166. [CrossRef]

6. Fabbian, D.; de Dear, R.; Lellyett, S. Application of artificial neural network forecasts to predict fog at Canberra International Airport. Weather Forecast. 2007, 22, 372-381. [CrossRef]

7. Stolaki, S.; Pytharoulis, I.; Karacostas, T. A study of fog characteristics using a coupled WRF-COBEL model over Thessaloniki airport, Greece. Pure Appl. Geophys. 2012, 169, 961-981. [CrossRef]

8. Jia, X.C.; Quan, J.N.; Zheng, Z.Y.; Liu, X.G.; Liu, Q.; He, H.; Liu, Y.G. Impacts of anthropogenic aerosols on fog in North China Plain. J Geophys. Res. Atmos. 2019, 124, 252-265. [CrossRef]

9. Liu, C.W.; Gao, Z.Q.; Li, Y.B.; Gao, C.Y.; Su, Z.B.; Zhang, X.Y. Surface Energy Budget Observed for Winter Wheat in the North China Plain During a Fog-Haze Event. Bound. Layer Meteorol. 2019, 170, 489-505. [CrossRef]

10. Rémy, S.; Bergot, T. Assessing the impact of observations on a local numerical fog prediction system. Q. J.R. Meteorol. Soc. 2009, 135, 1248-1265. [CrossRef]

11. Cuxart, J.; Jiménez, M.A. Deep radiation fog in a wide closed valley: Study by numerical modeling and remote sensing. Pure Appl. Geophys. 2012, 169, 911-926. [CrossRef]

12. Bergot, T. Large-eddy simulation study of the dissipation of radiation fog. Q. J. R. Meteorol. Soc. 2016, 142, 1029-1040. [CrossRef]

13. Maalick, Z.; Kühn, T.; Korhonen, H.; Kokkola, H.; Laaksonen, A.; Romakkaniemi, S. Effect of aerosol concentration and absorbing aerosol on the radiation fog life cycle. Atmos. Environ. 2016, 133, $26-33$. [CrossRef]

14. Zhou, B.B.; Du, J.; Gultepe, I.; Dimego, G. Forecast of low visibility and fog from NCEP: Status and efforts. Pure Appl. Geophys. 2012, 169, 895-909. [CrossRef]

15. Stolaki, S.; Haeffelin, M.; Lac, C.; Dupont, J.C.; Elias, T.; Masson, V. Influence of aerosols on the life cycle of a radiation fog event. A numerical and observational study. Atmos. Res. 2015, 151, 146-161. [CrossRef]

16. Heo, K.Y.; Ha, K.J.; Mahrt, L.; Shim, J.S. Comparison of advection and steam fogs: From direct observation over the sea. Atmos. Res. 2010, 98, 426-437. [CrossRef]

17. Boers, R.; Baltink, H.K.; Hemink, H.J.; Bosveld, F.C.; Moerman, M. Ground-based observations and modeling of the visibility and radar reflectivity in a radiation fog layer. J. Atmos. Ocean. Tech. 2013, 30, 288-300. [CrossRef]

18. Liu, D.Y.; Yang, J.; Niu, S.J.; Li, Z.H. On the evolution and structure of a radiation fog event in Nanjing. Adv. Atmos. Sci. 2011, 28, 223-237. [CrossRef]

19. Bergot, T. Small-scale structure of radiation fog: A large-eddy simulation study. Q. J. R. Meteorol. Soc. 2013, 193, 1099-1112. [CrossRef]

20. Cai, Z.Y.; Han, S.Q.; Wu, B.G.; Huang, H.; Yao, Q. Analysis on Characteristics of Atmospheric Boundary Layer During a Fog Process in Tianjin. Meteorol. Mon. 2012, 38, 1103-1109, (In Chinese with English Abstract). 
21. Sorli, B.; Pascal-Delannoy, F.; Giani, A.; Foucaran, A.; Boyer, A. Fast humidity sensor for high range 80-95\% RH. Sensor. Actuat. A: Phys. 2002, 100, 24-31. [CrossRef]

22. Huang, H.J.; Liu, H.N.; Huang, J.; Mao, W.K.; Bi, X.Y. Atmospheric boundary layer structure and turbulence during sea fog on the southern China coast. Mon. Weather Rev. 2015, 143, 1907-1923. [CrossRef]

23. Guo, J.T.; Li, P.Y.; Fu, G.; Zhang, W.; Gao, S.H.; Zhang, S.P. The structure and formation mechanism of a sea fog event over the Yellow Sea. J. Ocean Univ. China 2015, 14, 27-37. [CrossRef]

24. Li, Z.H.; Liu, D.Y.; Yan, W.L.; Wang, H.B.; Zhu, C.Y.; Zhu, Y.Y.; Zu, F. Dense fog burst reinforcement over Eastern China: A review. Atmos. Res. 2019, 230, 104639. [CrossRef]

25. Dabas, A.; Remy, S.; Bergot, T. Use of a sodar to improve the forecast of fogs and low clouds on airports. Pure Appl. Geophys. 2012, 169, 769-781. [CrossRef]

26. Wu, D.; Lu, B.; Zhang, T.C.; Yan, F.Q. A method of detecting sea fogs using CALIOP data and its application to improve MODIS-based sea fog detection. J. Quant. Spectrosc. Ra. 2015, 153, 88-94. [CrossRef]

27. Van der Velde, I.R.; Steeneveld, G.J.; Wichers Schreur, B.G.J.; Holtslag, A.A.M. Modeling and forecasting the onset and duration of severe radiation fog under frost conditions. Mon. Weather Rev. 2010, 138, 4237-4253. [CrossRef]

28. Marchand, R.; Ackerman, T.; Smyth, M.; Rossow, W.B. A review of cloud top height and optical depth histograms from MISR, ISCCP, and MODIS. J. Geophys. Res. Atmos. 2010, 115, D16206. [CrossRef]

29. Yi, L.; Zhang, S.P.; Thies, B.; Shi, X.M.; Trachte, K.; Bendix, J. Spatio-temporal detection of fog and low stratus top heights over the Yellow Sea with geostationary satellite data as a precondition for ground fog detection-A feasibility study. Atmos. Res. 2015, 151, 212-223. [CrossRef]

30. Liu, Y.H.; Key, J.R. Detection and analysis of clear-sky, low-level atmospheric temperature inversions with MODIS. J. Atmos. Ocean. Tech. 2003, 20, 1727-1737. [CrossRef]

31. Cermak, J.; Bendix, J. Detecting ground fog from space-A microphysics-Based approach. Int. J. Remote Sens. 2011, 32, 3345-3371. [CrossRef]

32. Cermak, J.; Bendix, J. A novel approach to fog/low stratus detection using Meteosat 8 data. Atmos. Res. 2008, 87, 279-292. [CrossRef]

33. Román-Cascón, C.; Yagüe, C.; Steeneveld, G.J.; Sastre, M.; Arrillaga, J.A.; Maqueda, G. Estimating fog-top height through near-surface micrometeorological measurements. Atmos. Res. 2016, 170, 76-86. [CrossRef]

34. Quan, J.N.; Zhang, Q.; He, H.; Liu, J.; Huang, M.Y.; Jin, H. Analysis of the formation of fog and haze in North China Plain (NCP). Atmos. Chem. Phys. 2011, 11, 8205-8214. [CrossRef]

35. Han, S.Q.; Cai, Z.Y.; Zhang, Y.F.; Wang, J.; Yao, Q.; Li, P.Y.; Li, X.J. Long-term trends in fog and boundary layer characteristics in Tianjin, China. Particuology 2015, 20, 61-68. [CrossRef]

36. Stewart, I.D.; Oke, T.R. Local climate zones for urban temperature studies. Bull. Am. Meteorol. Soc. 2012, 93, 1879-1900. [CrossRef]

37. Vickers, D.; Mahrt, L. Quality control and flux sampling problems for tower and aircraft data. J. Atmos. Ocean. Tech. 1997, 14, 512-526. [CrossRef]

38. Wilczak, J.M.; Oncley, S.P.; Stage, S.A. Sonic anemometer tilt correction algorithms. Bound. Layer Meteorol. 2001, 99, 127-150. [CrossRef]

39. Finnigan, J.J.; Clement, R.; Malhi, Y.; Leuning, R.; Cleugh, H.A. A re-evaluation of long-term flux measurement techniques part I: Averaging and coordinate rotation. Bound. Layer Meteorol. 2003, 107, 1-48. [CrossRef]

40. Ye, X.X.; Wu, B.G.; Zhang, H.S. The turbulent structure and transport in fog layers observed over the Tianjin area. Atmos. Res. 2015, 153, 217-234. [CrossRef]

41. Ren, Y.; Zhang, H.S.; Wei, W.; Wu, B.G.; Liu, J.L.; Cai, X.H.; Song, Y. Comparison of the turbulence structure during light and heavy haze pollution episodes. Atmos. Res. 2019, 230, 104645. [CrossRef]

42. Duynkerke, P.G. Radiation fog: A comparison of model simulation with detailed observations. Mon. Weather Rev. 1991, 119, 324-341. [CrossRef]

43. Businger, J.A.; Wyngaard, J.C.; Izumi, Y.; Bradley, E.F. Flux-profile relationships in the atmospheric surface layer. J. Atmos. Sci. 1971, 28, 181-189. [CrossRef]

44. Dyer, A.J. A review of flux-profile relationships. Bound. Layer Meteorol. 1974, 7, 363-372. [CrossRef]

45. Brown, R.; Roach, W.T. The physics of radiation fog: II-A numerical study. Q. J. R. Meteorol. Soc. 1976, 102, 335-354. [CrossRef]

46. Zhou, B.B.; Ferrier, B.S. Asymptotic Analysis of Equilibrium in Radiation Fog. J. Appl. Meteorol. Clim. 2008, 47, 1704-1722. [CrossRef] 
47. Ding, Y.H.; Liu, Y.J. Analysis of long-term variations of fog and haze in China in recent 50 years and their relations with atmospheric humidity. Sci. China Earth Sci. 2014, 57, 36-46. [CrossRef]

48. Doyle, M.; Dorling, S. Visibility trends in the UK 1950-1997. Atmos. Environ. 2002, 36, 3161-3172. [CrossRef]

49. Vautard, R.; Yiou, P.; Van Oldenborgh, G.J. Decline of fog, mist, and haze in Europe over the past 30 years. Nat. Geosci. 2009, 2, 115. [CrossRef]

50. Liu, D.Y.; Niu, S.J.; Yang, J.; Zhao, L.J.; Lü, J.J.; Lu, C.S. Summary of a 4-year fog field study in northern Nanjing, Part 1: Fog boundary layer. Pure Appl. Geophys. 2012, 169, 809-819. [CrossRef]

51. Price, J.D. On the Formation and Development of Radiation Fog: An Observational Study. Bound. Layer Meteorol. 2019, 1-31. [CrossRef]

52. Price, J. Radiation fog. Part I: Observations of stability and drop size distributions. Bound. Layer Meteorol. 2011, 139, 167-191. [CrossRef]

53. Bari, D.; Bergot, T.; El Khlifi, M. Numerical study of a coastal fog event over Casablanca, Morocco. Q. J. R. Meteorol. Soc. 2015, 141, 1894-1905. [CrossRef]

(C) 2020 by the authors. Licensee MDPI, Basel, Switzerland. This article is an open access article distributed under the terms and conditions of the Creative Commons Attribution (CC BY) license (http://creativecommons.org/licenses/by/4.0/). 